\title{
Catastrophic Wear in a Metal-On-Ceramic Total Hip Arthroplasty
}

\author{
Juan Ramón Valentí, PhD, MD \\ Javier Del Río, MD \\ Santiago Amillo, PhD, MD
}

From the Department of Orthopedic Surgery and Traumatology, University Clinic of Navarre, Navarre, Spain.

No benefits or funds were received in support of the study.

Reprint requests: Juan Ramon Valentí, PhD, MD, Pío XII 36, 31008 Pamplona, Spain.

\begin{abstract}
A 51-year-old woman came to our clinic 6 months after a right total hip arthroplasty. She had noticed a slowly growing mass in the proximal thigh and referred progressive pain in the right groin. Plain radiography revealed premature acetabular cup aseptic loosening, and in the computed tomography study, a 14-cm-diameter mass was observed. Revision surgery was performed, showing a metal-on-ceramic bearing surface. The histologic analysis of surrounding tissues was reported as massive metallosis. Although occasionally chosen for primary or revision hip arthroplasty, there is little information available about the in vivo wear behavior of this combination. This important fact should be taken into account before considering such a surface alternative.
\end{abstract}

Key words: wear, bearing surface, total hip arthroplasty, ceramic-on-metal, metal-onmetal.

\section{INTRODUCTION}

One of the main objectives in total hip arthroplasty (THA) is to improve implant longevity. To make this possible, understanding the mechanisms of wear between the interacting surfaces is essential. The tribological properties of bearing surfaces are one of the main topics in discussion in the orthopedic community.

There are multiple alternatives for bearing surfaces, each has specific characteristics that the surgeon must consider at the time of surgery [1,2]. Basically for acetabular cup materials, those in use include ceramic, polyethylene, and metal, and for the femoral head, ceramic and metal. The recommended combinations between these materials arise from in vitro studies, performed by investigators and manufacturers, and from clinical information reported in the literature.

Although information on tribological considerations in THA is extensive, reports about clinical evolution of patients with unproven or incompatible bearing surfaces are limited. We report a case of a patient who came to our clinic with metal-on-ceramic THA and describe the clinical evolution and the associated complications related to this pairing. 


\section{PATIENT AND METHOD}

\section{Case Report}

A 51-year-old woman had a bilateral hip pros-thesis in another hospital because of osteoarthritis. She came to our clinic 6 months after the right hip surgery reporting that after 6 weeks of initially favor able progress, she experienced pain in the right groin and gluteus maximus area. In addition, the patient had noticed during the last month a slowly growing mass in the proximal thigh.

Physical examination revealed an antalgic gait, flexion contracture of $20^{\circ}$, painful decreased hip motion with maximum flexion of $80^{\circ}$, and a palpable mass on the anterior and lateral side of the proximal third of the thigh. The patient's weight was $69 \mathrm{~kg}$, height was $152 \mathrm{~cm}$, and body mass index was $29.8 \mathrm{~kg} / \mathrm{m}^{2}$. Plain hip radiography showed acetabular loosening and an important increase in soft tissue density (Fig. 1). White blood cell count was $5.3 \times 10^{9} / \mathrm{L}$, the erythrocyte sedimentation rate was $34 \mathrm{~mm}$ in the first hour, and C-reactive protein was $3 \mathrm{mg} / \mathrm{L}$. All the other blood analyses were normal.

In a computed tomography hip scan, a 14-cm-diameter mass was observed in relation to the right hip. It involved the areas that corresponded to the acetabulum, gluteus medius, and maximus, and extended toward the proximal femur (Fig. 2). ${ }^{99}$ Tc scan showed a focal area of increased uptake in the posterior acetabulum. No areas of increased uptake were seen on the ${ }^{67} \mathrm{Ga}$ scan, making infection unlikely.

After hospital admission, a biopsy of the mass was done, which revealed a granulomatous reaction with massive metallosis. With these results, removal of the implant was performed. During surgery, it was observed that the mass was composed of a collection of black, dense material. When the prosthetic components were extracted, it became evident that the bearing surface was metal-on-ceramic. The acetabular cup was loose, whereas the femoral stem was well fixed. Specifically, retrieved components included hydroxyapatite-coated titanium uncemented femoral stem, 28-mm stainless steel head, and in the acetabulum, a 28/48 uncemented titanium shell with an alumina ceramic insert. Macroscopic wear was observed in both surfaces (Fig. 3). All necrotic tissue and foreign materials were removed. Intraoperative cultures were negative for aerobic and anaerobic bacteria. Histologic analysis of surrounding tissues obtained during surgery confirmed the preoperative biopsy results.

One year after excision arthroplasty, reimplantation was carried out. We used a BurchSchneider antiprotrusio cage and a Müller cemented femoral stem. A metal-onpolyethylene bearing surface was chosen. Two years after surgery, the patient is painfree, walks without ambulatory aids, and control plain radiography shows no implant loosening.

\section{DISCUSSION}

Hard-on-hard bearings are one of the ways to reduce wear rates. Studies and tribology fora focus on metal-on-metal or ceramic-on-ceramic combinations. Stewart et al [3] reported severe wear of zirconia heads against alumina inserts in hip simulator studies with microseparation (separation of the ball and socket during the swing phase of 
walking). Keel and Kuster [4] reported massive wear with a stainless steel head against a Co-Cr-Mo inlay. Modern hard-on-hard bearing low wear rates depend on the correct pairing of bearing surfaces and strict manufacturing tolerances in surface roughness, clearance, and roundness [2,5].

Although there is an in vitro study that reports reduced wear rates of ceramic-on-metal compared with metal-on-metal pairings [6], it does not consider in vivo phenomena like microseparation or third body particles (not observed in our patient). Apparently, microseparation affects ceramic-on-ceramic bearing surfaces [3,7] but does not occur in metal-on-metal THA [8]. Cup loosening might have contributed to the intense reaction observed in relation to this bearing surface, although there was no macroscopic wear on the other surface. In vivo wear behavior of metal-on-ceramic pair is currently unknown. The consequences of implanting a metal-on-ceramic combination are not completely determined. Short-term effect of this pair, in our patient, included premature wear, aseptic loosening, and granulomatous reaction in the surrounding soft tissues. The longterm effect of this association must be a matter of research.

Metallosis was evident during surgery and in the periprosthetic tissue histologic assessment. The local and systemic effects of these particles are not completely clear. Lymphatic dissemination of metallic wear particles has been observed [9], and there are numerous reports of increased serum levels of metal ions after metal-on-metal hip arthroplasty [10]. As reported in the literature, measurements of serum levels of metals might have been useful for initial diagnosis [11]. Apparently, there is no increase in the incidence of malignancies in patients exposed to metal particles [12], but in patients with metal-on-metal bearings, hypersensitivity to metals is higher than in normal population, especially in those with failed implants $[9,13]$. Massive wear and extensive metallosis must be avoided.

We consider that metal-on-ceramic is not a recommendable alternative for primary hip arthroplasty, at least until more studies of in vivo behavior are reported.

\section{REFERENCES}

1. Knahr K, Oberholzer St, Pinggera O. Tribological considerations in primary and revision in hip arthroplasty. In: Rieker C, editor. World Tribology Forum in Arthroplasty. Bern: Hans Huber; 2001. p. 67.

2. Campbell P, Shen FW, McKellop H. Biologic and tribologic considerations of alternative bearing surfaces. Clin Orthop Relat Res 2004;98.

3. Stewart TD, Tipper JL, Insley G, et al. Severe wear and fracture of zirconia heads against alumina inserts in hip simulator studies with microseparation. J Arthroplasty 2003;18:726.

4. Keel JB, Kuster MS. Massive wear of an incompatible metal-on-metal articulation in total hip arthroplasty. J Arthroplasty 2004;19:638.

5. Wagner $\mathrm{M}$, Wagner $\mathrm{H}$. Medium-term results of a modern metal-on-metal system in total hip replacement. Clin Orthop Relat Res 2000;123.

6. Firkins PJ, Tipper JL, Ingham E, et al. A novel low wearing differential hardness, ceramic-on-metal hip joint prosthesis. J Biomech 2001;34:1291. 
7. Nevelos J, Ingham E, Doyle C, et al. Microseparation of the centers of aluminaalumina artificial hip joints during simulator testing produces clinically relevant wear rates and patterns. J Arthroplasty 2000;15:793.

8. Komistek RD, Dennis DA, Ochoa JA, et al. In vivo comparison of hip separation after metal-on-metal or metal-on-polyethylene total hip arthroplasty. J Bone Joint Surg Am 2002;84:1836.

9. Urban RM, Jacobs JJ, Tomlinson MJ, et al. Dissemination of wear particles to the liver, spleen, and abdominal lymph nodes of patients with hip or knee replacement. J Bone Joint Surg Am 2000;82:457.

10. Lhotka C, Szekeres T, Steffan I, et al. Four-year study of cobalt and chromium blood levels in patients managed with two different metal-on-metal total hip replacements. J Orthop Res 2003;21:189.

11. Jacobs JJ, Skipor AK, Campbell PA, et al. Can metal levels be used to monitor metal-on-metal hip arthroplasties? J Arthroplasty 2004;19(8 Suppl 3):59.

12. Visuri T, Pukkala E, Paavolainen P, et al. Cancer risk after metal on metal and polyethylene on metal total hip arthroplasty. Clin Orthop Relat Res 1996;(329 Suppl):S280.

13. Hallab N, Merritt K, Jacobs JJ. Metal sensitivity in patients with orthopaedic implants. J Bone Joint Surg Am 2001;83:428. 


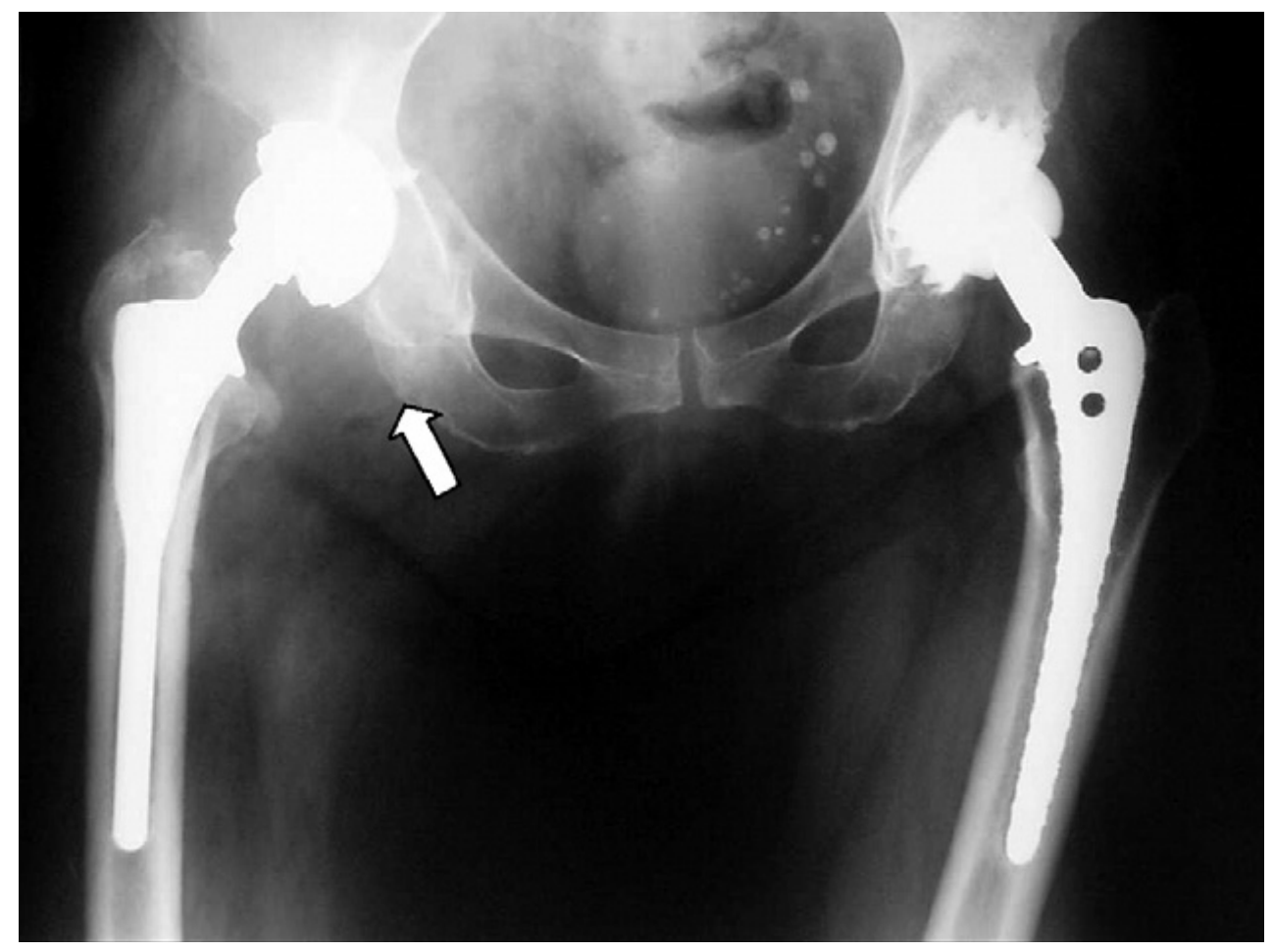

Fig.1 Anteroposterior plain radiography showing acetabular mobilization and increased soft tissue density on the right hip (arrow).

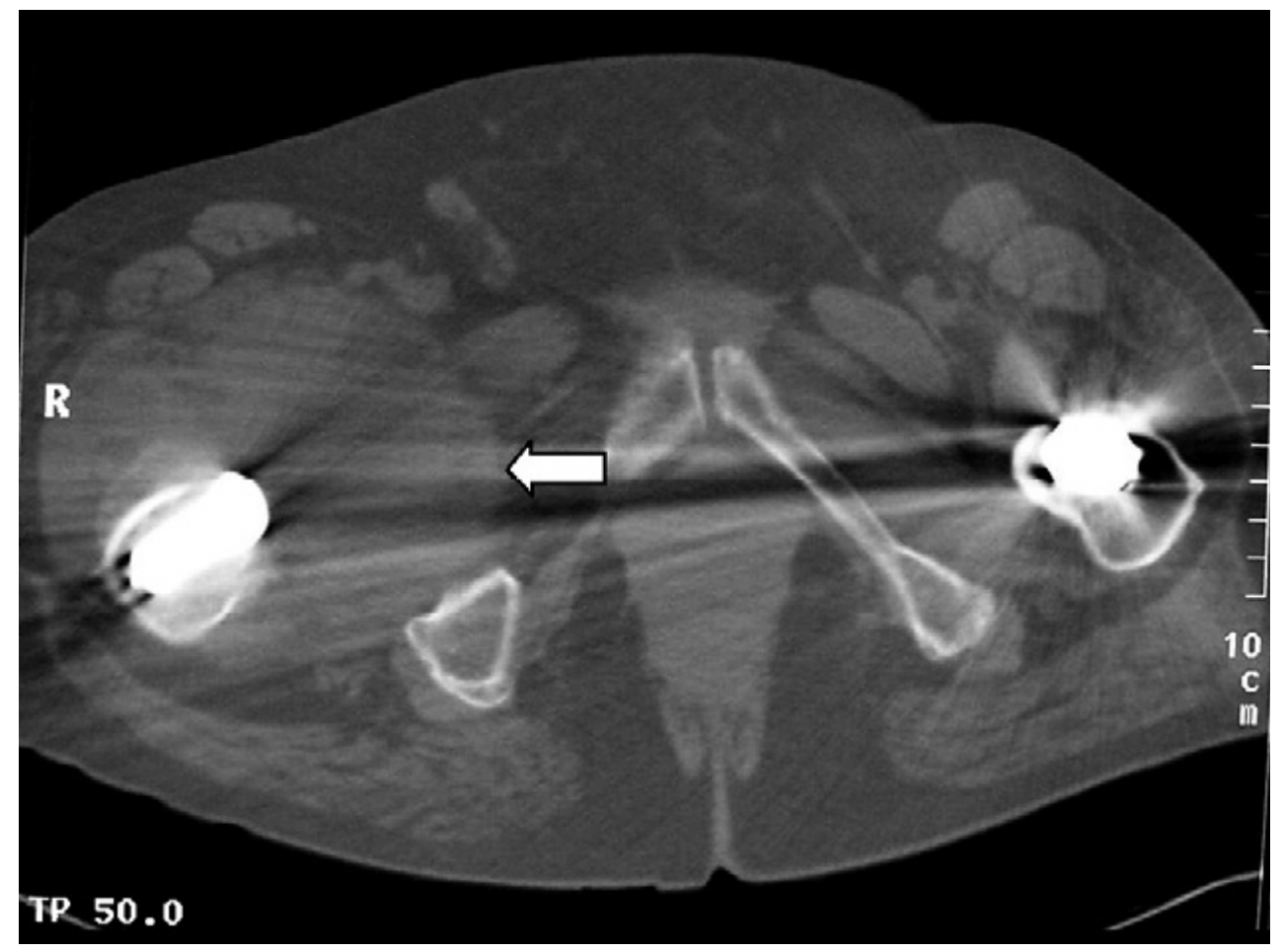

Fig. 2 Computed tomography scan of the hips demonstrating a 14-cm-diameter mass in relation to the right femoral stem (arrow). 


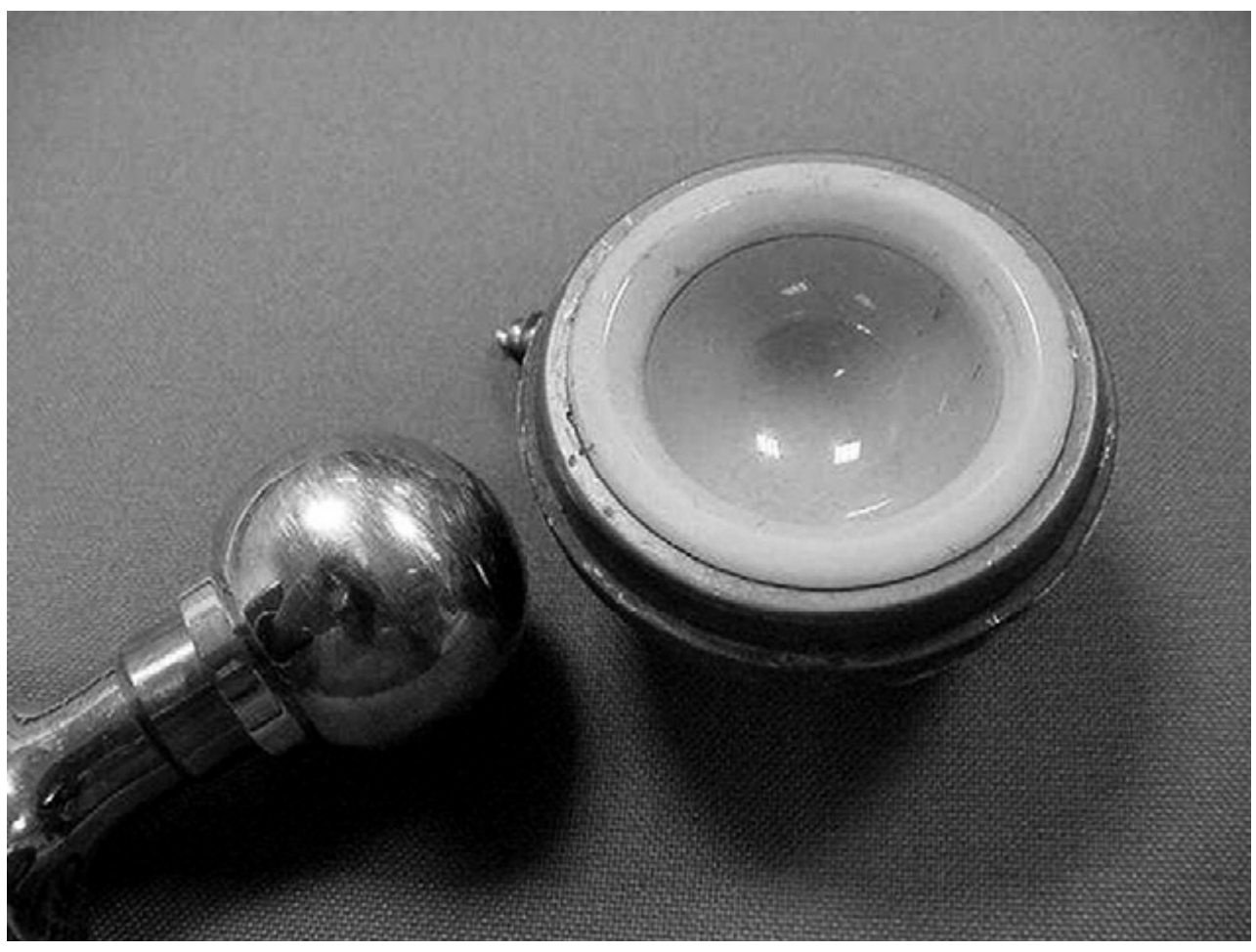

Fig. 3 Photograph of the retrieved components showing that the bearing surface was a stainless steel head and an alumina ceramic acetabular inlay. Macroscopic wear was evident on both surfaces. 